\title{
15 Years of Altimetry at Various Scales over the Mediterranean
}

\author{
Paolo Cipollini ${ }^{1}$, Stefano Vignudelli ${ }^{2}$, Florent Lyard ${ }^{3}$, and Laurent Roblou ${ }^{4}$ \\ ${ }^{1}$ National Oceanography Centre, Southampton, UK \\ ${ }^{2}$ Consiglio Nazionale delle Ricerche, Istituto di Biofisica, Pisa, Italy \\ ${ }^{3}$ Laboratoire d'Etude en Géophysique et Océanographie Spatiale, Toulouse, \\ France \\ ${ }^{4}$ Noveltis, Ramonville-Saint-Agne, France
}

\begin{abstract}
The present article reviews the application of altimetry in the Mediterranean Sea, to study the circulation and sea surface height variability, both at basin scale and in specific regions. The improvements needed to fully exploit the 15-year record of data close to the coast are also discussed. These range from improved tidal models, to specialized atmospheric corrections, to ad hoc screening of data in proximity of the coast. Some of these improvements are already underway while others are the focus of forthcoming programs.
\end{abstract}

\section{Introduction and rationale}

Understanding the oceanic variability of the Mediterranean Sea and its response to global climate change is crucial to predict its evolution, its feedback on regional climate, and its impact on socio-economic activities along its coasts. Other contributions to this book deal with changes in wave climate and new applications of altimetry and reconstructions of long-term sea level variations (described elsewhere in the present volume). Here we focus on the variability in Mediterranean circulation as inferred from altimetry, covering a wide range of spatial scales (coastal to basin) and temporal scales (weekly to decadal). First we review the main findings from basin-wide studies, then we look at results over specific regions and finally we discuss current and planned research aiming at improving the quality of altimetric data over the basin and recovering as much information as possible near the coast. 


\section{Basin-wide studies of mediterranean variability}

Early studies, either with TOPEX/POSEIDON (T/P) data such as Larnicol et al. (1995) and Iudicone et al. (1998), or with ERS-1 data such as Vignudelli (1997a), demonstrated that altimetry is able to infer useful oceanographic information over the Mediterranean, but suffered from sampling limitations due to the use of a single mission, that aliased a significant part of the mesoscale circulation and of its variability.

A more successful approach has emerged with the merging of data from different missions, made possible both by the improvement in orbit determination and geophysical and instrumental corrections for the ERS satellites (Scharroo and Visser 1998; Le Traon and Ogor 1998) and by the development of techniques for the optimal intercalibration, merging and interpolation of multisatellite data. Fieguth et al. (1998) and Ayoub et al. (1998), for instance, improved considerably the resolution over the Mediterranean by merging T/P and ERS-1 data. The global mapping technique developed by Le Traon et al. (1998) and Ducet et al. (2000) and currently adopted for the generation of data by SSALTO/DUACS, has allowed basin-wide studies making the most of the improved resolution, including Larnicol et al. (2002) who were able to characterize the major changes in sea level variability for the 1993-1999 period and found important interannual signals in the Ionian basin, and Pujol and Larnicol (2005).

In the early years of this decade, the simultaneous availability of up to five altimeters (T/P, ERS-2, EnviSat RA, Jason-1 and GFO) has resulted into a further improvement of the capability of multimission altimeter datasets to capture the mesoscale. Pascual et al. (2007) have recently revisited this issue over the Mediterranean, and show that a four-altimeter configuration allows a mapping of sea level and velocity with a relative accuracy of $6 \%$ and $23 \%$, respectively, and increase the average eddy kinetic energy over the basin by $15 \%$ with respect to a two altimeter (Jason-1 + ERS) configuration. Their conclusion is that at least three altimeters are needed to capture the mesoscale circulation.

Figure 1 represents the RMS variability over the period 1993-2006 of the SSALTO/DUACS regional multimission Sea Surface Height Anomaly (SSHA) for the Mediterranean (the DT-MSLA merged "Upd" product) distributed by AVISO, and highlights some areas of enhanced variability, most notably the Alboran Gyres, the Algerian Basin, the Ionan Basin, and the Ierapetra Gyre SE of Crete. The dataset can be analyzed in frequency space to illustrate the distribution of the different temporal scales of variability across the basin, as shown in Figure 2. In order to do this we have 
computed the Fast Fourier Transform of the SSHA time series in any location and then partitioned the signal into frequency bands.

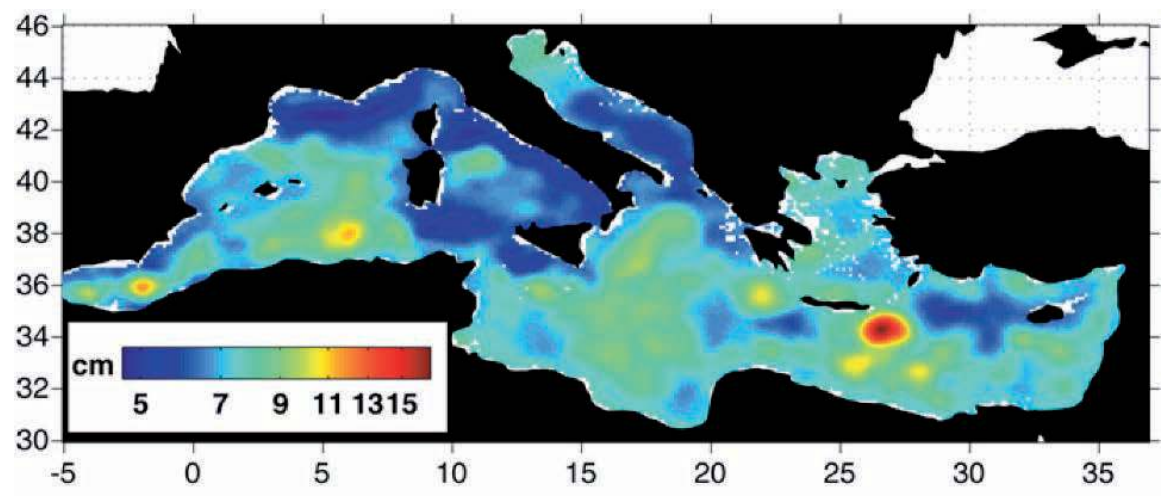

Fig. 1. RMS variability $(\mathrm{cm})$ of SSALTO/DUACS multimission SSHA (DTMSLA merged "Upd" product for the Mediterranean) over 1993-2006.

The low frequency variability map (Figure 2a) is dominated by a few regions that include the Ionian Sea, where a strong decreasing trend has been detected. The annual signal map in Figure $2 \mathrm{~b}$ shows a striking peak (with an amplitude in excess of 15 centimetres, i.e. more than $30 \mathrm{~cm}$ peakto-peak) in the Ierapetra Gyre, a narrow region which is also strongly energetic at periods longer than one year (also found to be virtually uncorrelated with the rest of the basin). Elsewhere the annual signal is almost uniform, with a small peak in the East Alboran Gyre, displaying significantly more variability at frequencies different from the annual one. The shorter time scales in Figures $2 \mathrm{c}, 2 \mathrm{~d}$ and $2 \mathrm{e}$ highlight several areas of known mesoscale activity, most notably in the Alboran Sea and Algerian Basin which peak at 1.5-4.5 months, whereas the high frequency signal ( $\mathrm{T}<1.5$ months) in Figure $2 \mathrm{f}$ is generally confined to a narrow coastal strip, a fact that underlines the need of a better temporal resolution of coastal dynamics, as we discuss below.

One important by-product of the merging of altimeter data with in situ data is the mean dynamic topography for the basin computed by Rio et al. (2007) and allowing a first estimation of absolute surface geostrophic currents. These clearly show many interesting patterns, such as the strong Mid-Mediterranean jet flowing along the coast of the Levantine basin, and several cyclonic/anticyclonic structures. This picture will further improve with the inclusion of gravimetric data, especially from the high-accuracy GOCE mission by ESA whose launch is scheduled for September 2007. 

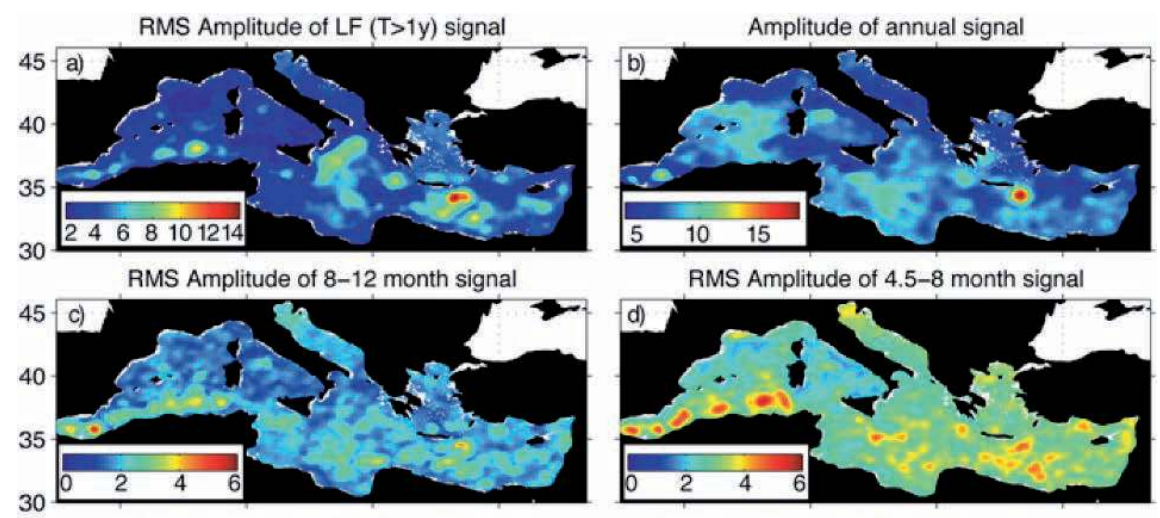

RMS Amplitude of $4.5-8$ month signal

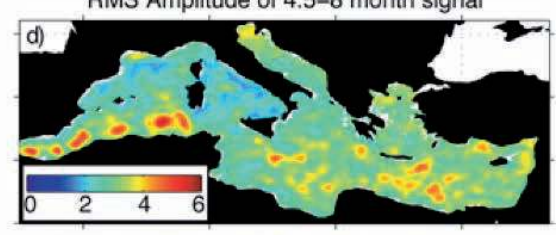

RMS Amplitude of 1.5-4.5 month signal
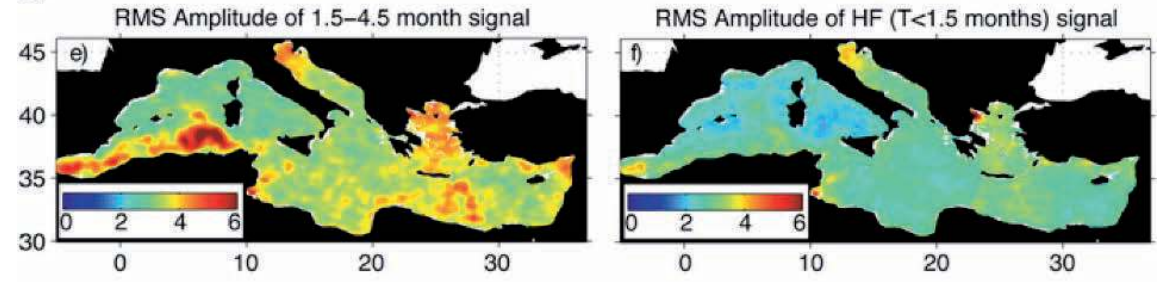

Fig. 2. Decomposition into spectral bands of the SSHA variability in Figure 1. All values are in cm. a) RMS amplitude of low-frequency signals (signals with period $>1$ year); b) amplitude of the single annual component; c) RMS amplitude of signals between 8 months and 1 year; d) RMS amplitude of signals between 4.5 and 8 months; e) RMS amplitude of signals between 1.5 and 4.5 months; f) RMS amplitude of high-frequency signals (signals with period $<1.5$ months)

\section{Applications of altimetry to specific regions}

Several studies have applied altimetry to oceanographic problems over regional areas of the Mediterranean. Vignudelli (1997b) and Bouzinac et al. (1998) could detect the migration of anticyclonic eddies towards the interior of the Algerian Basin in T/P and ERS-1 data. Buongiorno Nardelli et al. (1999) combined altimeter and in situ observations in the Straits of Sicily to infer the 3-D structure of the circulation, in the first Mediterranean validation study of altimetry with hydrography, and found a strong barotropic component of the velocity field along the continental shelf. By including CTD casts from the MEDAR/MEDATLAS climatology and reconstructing the vertical structure through Coupled Pattern Reconstruction and multivariate EOFs, Buongiorno Nardelli et al. (2006) further clarify the important role of mesoscale processes in the area. 
Vignudelli et al. (2000) studied the forcing driving the flow through the Corsica Channel by comparing water transport anomalies from a currentmeter with altimeter-derived sea level differences between the two ends of the channel, whose time series are shown in Figure 3.

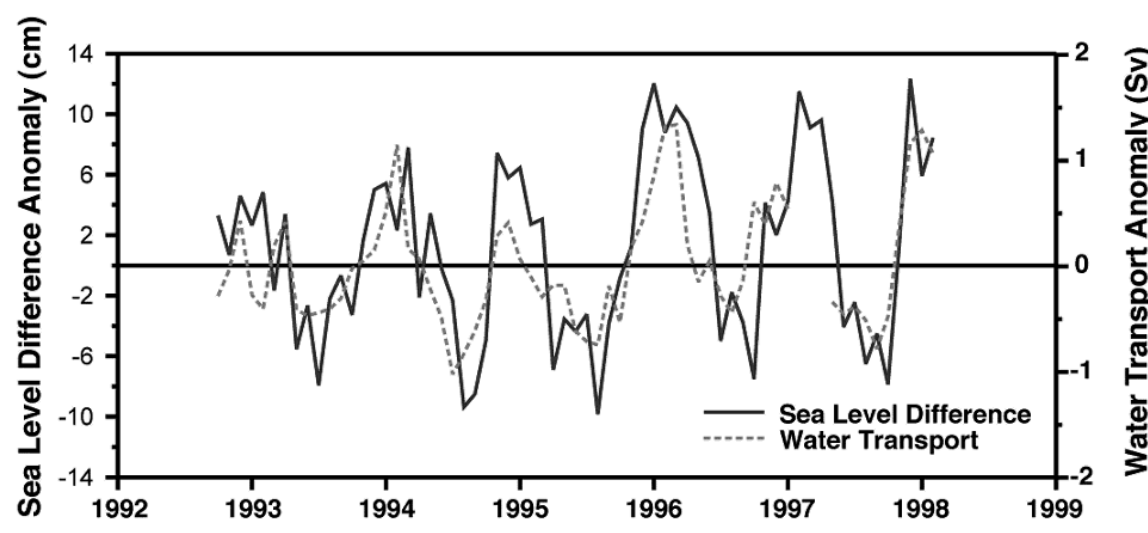

Fig. 3. Comparison of sea level difference between Tyrrhenian and Ligurian Seas, estimated along T/P track 044, and water transport from an in situ current-meter in the Corsica Channel (redrawn from Vignudelli et al. 2000).

The agreement between the seasonal current and the seasonal sea level difference indicates that the latter provides a significant component to the exchanges between the two basins, which in turn supports the findings by Astraldi and Gasparini (1992) that winter heat and water losses induced by air-sea interaction over the Liguro-Provencal Basin are important in driving the circulation of this part of the Mediterranean. Circulation in the Tyrrhenian and Ligurian seas was further investigated with a comparison between results from hydrographic (eXpendable Bathy-Thermograph, XBT) transects and altimeter data along the portion of T/P track 044 from Liguria to Sicily (Vignudelli et al. 2003). The comparison was done both in space (i.e. comparing near-simultaneous transects) and in time, and generally shows good agreement (within 2-4 cm RMS) for surface height changes associated with the time-varying part of the circulation. However this work did not include the segment of track 044 intersecting the channel (42.5$43.3 \mathrm{~N}$ ), due to the lack of XBT data. A T/P-Jason ground track crossing the Channel (track 085) has been recently investigated with the data editing techniques developed for coastal altimetry (Vignudelli et al. 2005), see below.

Observation of eddies continues to be an important application of altimetry, see for instance Pascual et al. (2002) who used altimetry, sea surface temperature and CTD data to study the formation and evolution of an eddy 
in the Balearic Sea. A novel methodology for tracking of eddies in altimeter data, based on identifying closed contours of a parameter that measures the relative importance of deformation and rotation, has been developed by Isern-Fontanet et al. (2003) who illustrated it with an example in the Algerian Basin. Recently, Isern-Fontanet et al. (2006) have used this technique over the entire Mediterranean, detecting complex but well-defined patterns of eddy propagation.

\section{Improving altimetry from basin-scale to the coasts}

Two fundamental challenges remain in altimetry over marginal seas: a) to improve the quality and availability of the corrections at regional scale and/or basin scale; and b) to recover a quality-controlled altimetric datum as close as possible to the coast. This would give access to 15 years of unexploited data, certainly a very valuable asset to study coastal dynamics. An overview of these two issues was carried out by Anzenhofer et al. (1999), who described the generation of coastal altimeter data, discussed various retracking algorithms and their implementation and showed some examples based on the intermediate ERS waveform data. They concluded with recommendations on better (local) tidal modelling, careful screening of the data, improvement of the wet tropospheric correction and retracking.

The Mediterranean Sea, unique for its complex morphology of subbasins bounded by an intricate shoreline and showing a huge variety of oceanographic features, is the perfect site to tackle the challenges described above. It is therefore not surprising that this basin has been the main focus of a few initiatives in the above direction.

An early attempt to custom-process coastal ERS-1 altimetric records was made by Manzella et al. (1997) around Corsica. They used a regional tidal model (Tsimplis et al. 1995), recomputed the wet tropospheric correction by recalibrating the model correction with the closest available radiometric estimate, and recovered measurements previously flagged as bad because of a high $\sigma_{0}$ value induced by sea surface flatness.

The ideas of customized tidal modelling and de-flagging were also followed by Vignudelli et al. (2000) over the Corsica Channel, using $1 \mathrm{~Hz}$ T/P data in combination with current meter and tide gauge data. Results were encouraging, showing that with simple improvements in the processing, the signal recovered at seasonal time scales was in good agreement with the in situ measurements and allowed useful oceanographic conclusions.

The concepts laid out by those pilot studies have been extended to the whole Northwest Mediterranean in the joint French-Italian ALBICOCCA 
(ALtimeter-Based Investigations in COrsica, Capraia and Contiguous Areas) initiative for coastal altimetry. Here we describe three key elements of the ALBICOCCA strategy for the generation of the coastal products: better tidal modelling, improved modelling of high frequency atmospheric effects, and screening of the data to recover information previously flagged as bad. These, in principle, are valid for all coastal regions. The improvements in the ALBICOCCA area are quantified in Vignudelli et al. (2005).

\subsection{Better tidal models}

The earlier studies mentioned above have demonstrated that global tidal models, despite their impressive improvement during the past decade, are generally not accurate enough over the shallow water areas to properly remove tidal effects in the altimeter measurements. Because of their insufficient spatial resolution (that does not resolve rapid changes in tidal features) and of incorrect frictional dissipation, usual global model cannot represent tides over continental shelves below a decimetre error level. If the tides are not accurately removed, the residual signal will mask other oceanographic phenomena, being aliased at their typical frequencies by the sampling pattern of the altimeter. To avoid this, as an alternative to the FES2004 (Lyard et al. 2006) or GOT00 global tidal solution available in the T/P Geophysical Data Records (GDRs), an optimised tidal spectrum has been defined for the Mediterranean Sea, mainly based on MOG2D regional tidal solutions (Carrère and Lyard 2003) and combined with global model FES2004 for the diurnal component.

As an illustration of the improvement in tidal modelling, Table 1 summarizes the misfits for the major tidal constituents for both the regional MOG2D solution and the FES2004 global solution relative to a reference tide gauge data set in the Mediterranean Sea. We can notice that for the semi-diurnal and $\mathrm{O} 1$ constituents the MOG2D solutions are generally better (lower in bias and/or significantly less dispersed) than the FES2004. Instead, for the main diurnal constituent K1 in the optimal spectrum we choose the FES2004 solution, due to the much larger MOG2D phase bias.

\subsection{Better correction of atmospheric effects}

The atmospherically forced high frequency signal can be a source of large aliasing in the altimetric records at mid- and high latitudes. Over the open ocean the effects of atmospheric pressure loading are corrected by the inverted barometer approximation, but significant departures can be observed over continental shelves and marginal seas. In reality, the sea level 
variations depend both statically and dynamically on the meteorological forcing whereas the IB approximation formulates merely the hydrostatic equilibrium between the sea level and the applied atmospheric pressure gradients. Moreover, the IB assumption totally ignores wind-forced sea level variations, which can prevail particularly around the altimetric sampling periods. An improved modelling of the level response, following Carrère and Lyard (2003), has therefore been carried out in the Mediterranean Sea, using a regional mesh (another outputs of the MOG2D model).

Table 1 . Comparison of LEGOS MOG2D Mediterranean Sea tides and FES2004 solutions with a reference tide gauge data set from 45 stations in the Mediterranean Sea.

\begin{tabular}{lllrl}
\hline \multirow{2}{*}{ Tidal constituent } & $\begin{array}{l}\text { Amplitude } \\
\text { difference }(\mathrm{cm})\end{array}$ & $\begin{array}{l}\text { Phase lag } \\
\text { (degrees) }\end{array}$ & $\begin{array}{l}\text { Complex difference } \\
\text { modulus }(\mathrm{cm})\end{array}$ \\
\hline \multirow{2}{*}{ M2 } & FES2004 & $-0.1+/-1.4$ & $1.2+/-17.7$ & $0.6+/-1.6$ \\
& MOG2D & $0.0+/-1.0$ & $1.3+/-9.3$ & $0.2+/-1.3$ \\
\hline \multirow{2}{*}{ S2 } & FES2004 & $-0.3+/-0.8$ & $-5.8+/-20.5$ & $0.4+/-1.2$ \\
& MOG2D & $0.3+/-0.5$ & $-1.6+/-16.9$ & $0.1+/-0.7$ \\
\hline \multirow{2}{*}{ N2 } & FES2004 & $-0.2+/-0.4$ & $4.5+/-22.5$ & $0.0+/-0.4$ \\
& MOG2D & $0.0+/-0.2$ & $-0.1+/-12.0$ & $0.0+/-0.3$ \\
\hline \multirow{2}{*}{ K1 } & FES2004 & $0.0+/-1.3$ & $3.0+/-13.9$ & $1.1+/-1.0$ \\
& MOG2D & $0.6+/-0.7$ & $15.5+/-12.7$ & $0.6+/-1.0$ \\
\hline \multirow{2}{*}{ O1 } & FES2004 & $0.2+/-0.4$ & $-8.8+/-16.1$ & $0.4+/-0.4$ \\
& MOG2D & $0.4+/-0.4$ & $10.0+/-13.6$ & $0.3+/-0.5$ \\
\hline
\end{tabular}

Table 2 illustrates the gain in sea level variance reduction in the short period range ( $\mathrm{T}<20$ days, where $\mathrm{T}$ is the period) when correcting sea level observations for 31 tide gauges with the global or regional MOG2D model instead of the IB parameterization.

Table 2. Residual sea level variance for $\mathrm{T}<20$ days when applying different atmospheric effect corrections to de-tided sea level at the 31 tide gauges around the Mediterranean for which data are available over the testing period (01/2002 to 06/2002).Values listed are the average of individual tide gauge variances.

\begin{tabular}{lllll}
\cline { 2 - 4 } & $\begin{array}{l}\text { No cor- } \\
\text { rection }\end{array}$ & $\begin{array}{l}\text { IB cor- } \\
\text { rected }\end{array}$ & $\begin{array}{l}\text { MOG2D- } \\
\text { Glob correct. }\end{array}$ & $\begin{array}{l}\text { Mog2D- } \\
\text { Med correct. }\end{array}$ \\
\cline { 2 - 5 } Residual variance $\left(\mathrm{cm}^{2}\right)$ & 26,34 & 15,32 & 6,97 & 5,11 \\
Variance reduction $(\%)$ & 42 & 75 & 79 \\
\cline { 2 - 5 } & & 42 & 75 & 79 \\
\hline
\end{tabular}




\subsection{Better screening of data}

In addition to the corrections described above, the ALBICOCCA processing adopted $a d$ hoc filtering and screening techniques allowing to recover data that otherwise would be flagged as bad (Roblou and Lyard 2004). Figure 4 shows an example of data recovery along T/P track 222 for cycle 95 (22/04/1995). The original (GDR) sea level anomalies are affected by abnormal values in the wet tropospheric correction, and therefore flagged as bad. De-flagging and re-interpolation of the correction yields a reconstructed level profile. This exercise has been extended over the entire NW Mediterranean; the improved products allow a better characterization of the variability at seasonal scales (see Vignudelli et al. 2005). Moreover, GPS campaigns have been carried out in the ALBICOCCA framework, for the definition of a local geoid connecting the altimeter tracks to the tide gauge sites in Corsica and Capraia (Bonnefond et al. 2003).
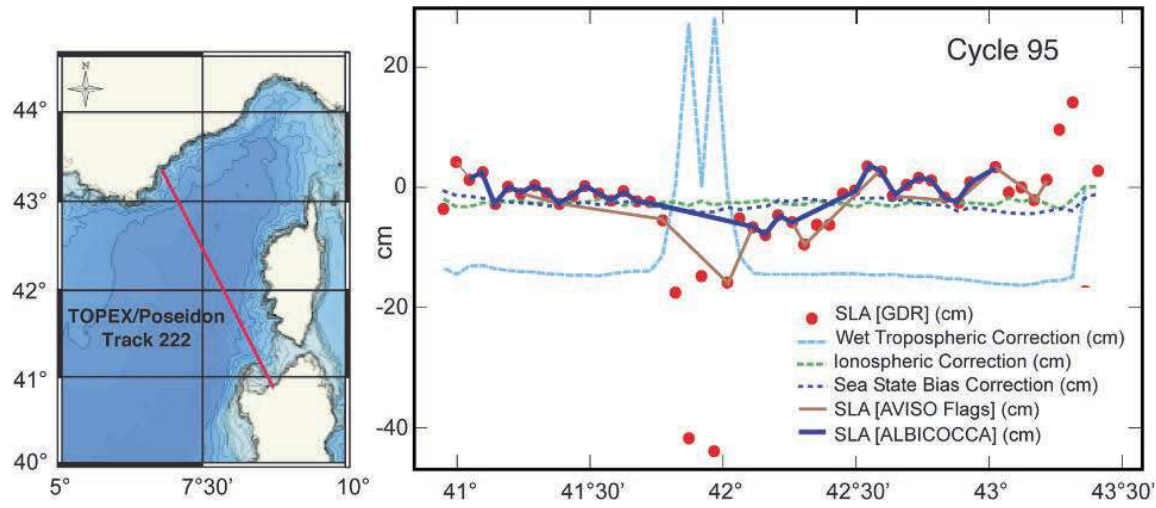

Fig. 4. Example of altimetric profile along track 222 for a given cycle (95) showing outliers in the wet troposphere correction. Red dots: uncorrected Sea Level Anomaly (SLA) and original corrections from the AVISO GDRs. Dashed lines: correction for atmospheric and surface effects. Solid brown line: SLA after application of the standard corrections from the GDR. Solid blue line: the new SLA profile after reconstructing the values with the ALBICOCCA technique described in Roblou and Lyard (2004).

\subsection{Present and future of coastal altimetry}

Several studies have dealt with the limitations of, and possible improvements to, coastal altimetry. The topic was the subject of a dedicated International Workshop in Beijing in July 2006, where Bouffard et al. (2006) 
presented preliminary results from exploiting a multi-mission scenario and higher along-track data rates in the NW Mediterranean.

The growing demand for readily available, reprocessed coastal altimetry data is about to be met by some initiatives that build on the activities described above. One of these is the ALTICORE ${ }^{1}$ (value-added ALTImetry for COastal REgions) project aiming at improving the monitoring capabilities of satellite altimeters over coastal areas. Access to distributed archives of data processed within ALTICORE will be via a Grid-compliant system, consisting of regional data centres, each having primary responsibility for regional archives, local corrections and quality control, and operating a set of web-services allowing access to the full functionality of data extraction (Vignudelli et al. 2006). This novel initiative focuses in particular on the European seas, including the Mediterranean and therefore reinforcing its role as the main laboratory for moving coastal altimetry towards operational status. It is complementary to other initiatives at European level, namely MERSEA ${ }^{2}$ (Marine EnviRonment and Security for the European Area), which focuses on operational oceanography, and ECOOP ${ }^{3}$ (European COastal sea OPerational observing and forecasting system), which aims at fine tuning MERSEA products to coastal applications.

\section{Acknowledgments}

The altimeter products were produced by SSALTO/DUACS and distributed by $\mathrm{AVISO}^{4}$ with support from CNES. Coastal altimeter data were produced by $\mathrm{CTOH}^{4}$.Current meter data were kindly provided by G.P. Gasparini and M. Astraldi of CNR/IOF La Spezia, Italy. ALTICORE is funded by INTAS (contract 05-1000008-7927)

\section{References}

Anzenhofer M, Shum CK, Rentsh M (1999) Coastal altimetry and applications, Tech Rep 464, Geodetic Science and Surveying, The Ohio State University Columbus, USA

\footnotetext{
${ }^{1}$ www.alticore.eu

${ }^{2}$ www.mersea.eu.org

${ }^{3}$ www.ecoop.eu

${ }^{4}$ www.aviso.oceanobs.com; www.legos.obs-mip.fr/observations/ctoh
} 
Astraldi M, Gasparini GP (1992) The seasonal characteristics of the circulation in the north Mediterranean basin and their relationship with the atmosphericclimatic conditions. J Geophys Res 97: 9531-9540

Ayoub N, Le Traon PY, De Mey P (1998) A description of the Mediterranean surface variable circulation from combined ERS-1 and TOPEX/POSEIDON altimetric data. J Mar Sys 18 (1/3): 3-40

Bonnefond P, Exertier P, Laurain O, Menard Y, Orsoni A, Jan G, Jeansou E (2003) Absolute Calibration of Jason-1 and TOPEX/Poseidon Altimeters in Corsica. Mar Geodesy 26 (3/4): 261-284

Bouffard J, Vignudelli S, Lyard F, Birol F, Marsaleix P, Roblou L, Menard Y, Gasparini GP, Manzella G, Cipollini P (2006) Advances in Coastal Altimetry over the Northwestern Mediterranean. In: International Workshop on coast and land applications of satellite altimetry, Beijing, July 21-22, pp 26-27

Bouzinac C, Vazquez J, Font J (1998) Complex empirical orthogonal functions analysis of ERS-1 and TOPEX/POSEIDON combined altimetric data in the region of the Algerian current. J Geophys Res 103 (C4): 8059-8071

Buongiorno Nardelli B, Santoleri R, Zoffoli S, and Marullo S (1999) Altimetric signal and three-dimensional structure of the sea in the Channel of Sicily. J Geophys Res 104 (C9): 20585-20603

Buongiorno Nardelli B, Cavalieri O, Rio MH, Santoleri R (2006) Subsurface geostrophic velocities inference from altimeter data: Application to the Sicily Channel (Mediterranean Sea). J Geophys Res 111: C04007

Carrère L, Lyard F (2003) Modeling the barotropic response of the global ocean to atmospheric wind and pressure forcing: comparisons with observations. Geophys Res Lett 30 (6): 1275-1285

Ducet N, Le Traon PY, Reverdin G (2000) Global high-resolution mapping of ocean circulation from the combination of T/P and ERS-1/2. J Geophys Res 105 (C8): 19477-19498

Fieguth P, Menemenlis D, Ho T, Willsky A, Wunsch C (1998) Mapping Mediterranean Altimeter Data with a Multiresolution Optimal Interpolation Algorithm. J Atmos Oceanic Tech 15: 535-546

Isern-Fontanet J, García-Ladona E, Font J (2003) Identification of marine eddies from altimetry. J Atmos Oceanic Technol 20: 772-778

Isern-Fontanet J, García-Ladona E, Font J (2006) Vortices of the Mediterranean Sea: An Altimetric Perspective. J Phys Ocean 36: 87-103

Iudicone D, Santoleri R, Marullo S, Gerosa P (1998) Sea level variability and surface eddy statistics in the Mediterranean Sea from TOPEX/POSEIDON data. J Geophys Res 103 (C2): 2995-3012

Larnicol G, Ayoub N, Le Traon PY (2002) Major changes in Mediterranean Sea level variability from 7 years of TOPEX/POSEIDON and ERS-1/2 data. J Mar Sys 33/34: 63-89

Larnicol G, Le Traon PY, Ayoub N, De Mey P (1995) Mean sea level and surface circulation variability of the Mediterranean Sea from 2 years of TOPEX/ POSEIDON altimetry. J Geophys Res 100 (C12): 25163-25177

Le Traon PY, Nadal F, Ducet N (1998) An improved mapping method of multisatellite altimeter data. J Atmos Oceanic Tech 15: 522-533 
Le Traon PY, Ogor F (1998) ERS-1/2 orbit improvement using TOPEX/ POSEIDON: The $2 \mathrm{~cm}$ challenge. J Geophys Res 103 (C4): 8045-8057

Lyard F, Lefevre F, Letellier T, Francis O (2006) Modelling the global ocean tides: modern insights from FES2004. Ocean Dynamics 56: 394-415

Manzella G, Borzelli GL, Cipollini P, Guymer TH, Snaith HM, Vignudelli S (1997) Potential use of satellite data to infer the circulation dynamics in a marginal area of the Mediterranean Sea. In: Proc 3rd ERS Symposium 3, ESA SP-414, pp 1461-466

Pascual A, Buongiorno Nardelli B, Larnicol G, Emelianov M, Gomis D (2002) A case of an intense anticyclonic eddy in the Balearic Sea (western Mediterranean). J Geophys Res 107 (C11): 3183-3193

Pascual A, Pujol MI, Larnicol G, Le Traon PY, Rio MH (2007) Mesoscale mapping capabilities of multisatellite altimeter missions: first results with real data in the Mediterranean Sea. J Mar Sys 65: 190-211

Pujol MI, Larnicol G (2005) Mediterranean sea eddy kinetic energy variability from 11 years of altimetric data. J Mar Sys 58: 121-142

Rio MH, Poulain PM, Pascual A, Mauri E, Larnicol G, Santoleri R (2007) A mean dynamic topography of the Mediterranean Sea computed from altimetric data, in-situ measurements and a general circulation model. J Mar Sys 65 (1-4): 484-508

Roblou L, Lyard F (2004) Retraitement des données altimétriques satellitaires pour des applications cotières en Mer Méditerranée. Tech Rep POC-TR-09 - 04, Pole d'Océanogr. Cotière, Toulouse, France

Scharroo R, Visser P (1998) Precise Orbit Determination and Gravity Field Improvement for the ERS Satellites. J Geophys Res 103: 8113-8127

Tsimplis MN, Proctor R, Flather RA (1995) A two-dimensional tidal model for the Mediterranean Sea. J Geophys Res 100: 16223-16239

Vignudelli S (1997a) Analysis of ERS-1 altimeter collinear passes in the Mediterranean Sea during 1992-1993. Int J Rem Sens 18 (3): 573-601

Vignudelli S (1997b) Potential use of ERS-1 and TOPEX/POSEIDON altimeters for resolving oceanographic patterns in the Algerian Basin. Geophys Res Lett 24 (14): 1787-1790

Vignudelli S, Cipollini P, Astraldi M, Gasparini GP, Manzella G (2000) Integrated use of altimeter and in situ data for understanding the water exchanges between the Tyrrhenian and Ligurian seas. J Geophys Res 105 (C8): 19649-19663

Vignudelli S, Cipollini P, Reseghetti F, Fusco G, Gasparini GP, Manzella G (2003) Comparison between XBT data and TOPEX/Poseidon satellite altimetry in the Ligurian-Tyrrhenian area. Annales Geophys 21: 123-135

Vignudelli S, Cipollini P, Roblou L, Lyard F, Gasparini GP, Manzella G, Astraldi M (2005) Improved satellite altimetry in coastal systems: Case study of the Corsica Channel (Mediterranean Sea). Geophys Res Lett 32: L07608

Vignudelli S, Snaith HM, Lyard F, Cipollini P, Birol F, Bouffard J, Roblou L (2006) Satellite radar altimetry from open ocean to coasts: challenges and perspectives. Proc SPIE 6406, 64060L: 1-12 